\title{
ALIMENTOS FUNCIONAIS E NUTRACÊUTICOS: DEFINIÇÕES, LEGISLAÇÃO E BENEFÍCIOS À SAÚDE.
}

\author{
Functional foods and nutraceuticals: definition, legislation and health benefits
}

\author{
Fernanda P. Moraes ${ }^{1}$ \& Luciane M. Colla ${ }^{2 *}$ \\ ${ }^{1}$ Acadêmica do Curso de Farmácia Industrial - Universidade de Passo Fundo - Passo Fundo, RS/ Brasil - \\ nandamoaraes2002@yahoo.com.br \\ ${ }^{2}$ Prof. do Curso de Farmácia Industrial - Universidade de Passo Fundo - Laboratório de Fermentações - Campus \\ I - Km 171 - BR 285, Bairro São José, Caixa Postal 611 - CEP 99001-970 - Passo Fundo/RS - (54) 3316-8193 I \\ Fax (54) 3316-8455
}

* Email para correspondência: Imcolla@upf.br

Recebido em 03/10/2006 - Aceito em 19/11/2006

RESUMO: Inúmeros fatores afetam a qualidade da vida moderna, de forma que a população deve conscientizarse da importância de alimentos contendo substâncias que auxiliam a promoção da saúde, trazendo com isso uma melhora no estado nutricional. A incidência de morte devido a acidentes cardiovasculares, câncer, acidente vascular cerebral, arteriosclerose, enfermidades hepáticas, dentre outros, pode ser minimizada através de bons hábitos alimentares. Os alimentos funcionais e os nutracêuticos comumente têm sido considerados sinônimos, no entanto, os alimentos funcionais devem estar na forma de alimento comum, serem consumidos como parte da dieta e produzir benefícios específicos à saúde, tais como a redução do risco de diversas doenças e a manutenção do bem-estar físico e mental. As substâncias biologicamente ativas encontradas nos alimentos funcionais podem ser classificadas em grupos tais como: probióticos e prebióticos, alimentos sulfurados e nitrogenados, pigmentos e vitaminas, compostos fenólicos, ácidos graxos poliinsaturados e fibras. Por outro lado, os nutracêuticos são alimentos ou parte dos alimentos que apresentam benefícios à saúde, incluindo a prevenção e/ou tratamento de doenças. Podem abranger desde os nutrientes isolados, suplementos dietéticos até produtos projetados, produtos herbais e alimentos processados. Objetivou-se comparar alimentos funcionais e nutracêuticos quanto à definição e legislação, apresentando as diferentes classes desses compostos e seus efeitos benéficos à saúde.

PALAVRAS CHAVES: alimentos funcionais, nutracêuticos, legislação, classificação.

ABSTRACT: Several factores affect the quality of modern life, therefore the population should be aware about the importance of foods containing substances that promote health, causing an improvement in the nutricional state. The incident of death due to cardiovascular problems, cancer, arteriosclerosos, hepatic diseases, among others, might be controlled trought good habits of feeding. Functional foods and nutraceutics have been considered to be synonymous. However, functional foods must be in the form of regular foods, be consumed as part of the diet and produce specific benefits to health, such as the reducing of the risk of several diseases and the maintenance of mental and physical well-being. The biologically active substances found in functional foods can be classified in groups, which will be presented in the development of this paper, for their important benefits to health. On the other hand, nutraceuticals are foods or part of foods that bring benefits to health, including prevention and/or treatment of diseases. It may include the isolated nutrients, dietary supplements, designed products, herbal products and processed foods. The aim of this work was to compare functional foods and nutraceuticals, based on definition and legislation, presenting the different classes of these compounds their beneficial effects to health.

KEYWORDS: functional foods, nutraceuticals, legislation, classification.

\section{INTRODUÇÃO}

A sociedade moderna tem se tornado cada vez mais complexa, modificando os padrões de vida. As pessoas freqüentemente mostram sintomas de cansaço, depressão e irritação, ou mais comumente uma forma de 
estresse (KWAK \& JUKES, 2001a). Apesar disto, a baixa incidência de doenças em alguns povos chamou a atenção para a sua dieta. Os esquimós, com sua alimentação baseada em peixes e produtos do mar ricos em ácidos graxos poliinsaturados das famílias ômega 3 e 6, têm baixo índice de problemas cardíacos, assim como os franceses, devido ao consumo de vinho tinto, o qual apresenta grande quantidade de compostos fenólicos. Os orientais devido ao consumo de soja, que contém fitoestrogênios, apresentam baixa incidência de câncer de mama. Nestes países, o costume de consumir frutas e verduras também resulta numa redução do risco de doenças coronarianas e de câncer, comprovada por dados epidemiológicos (ANJO, 2004).

"Os alimentos funcionais fazem parte de uma nova concepção de alimentos, lançada pelo Japão na década de 80 , através de um programa de governo que tinha como objetivo desenvolver alimentos saudáveis para uma população que envelhecia e apresentava uma grande expectativa de vida" (ANJO, 2004).

Os vários fatores que têm contribuído para o desenvolvimento dos alimentos funcionais são inúmeros, sendo um deles o aumento da consciência dos consumidores, que desejando melhorar a qualidade de suas vidas, optam por hábitos saudáveis.

Os alimentos funcionais devem apresentar propriedades benéficas além das nutricionais básicas, sendo apresentados na forma de alimentos comuns. São consumidos em dietas convencionais, mas demonstram capacidade de regular funções corporais de forma a auxiliar na proteção contra doenças como hipertensão, diabetes, câncer, osteoporose e coronariopatias (SOUZA, et al., 2003). Alimentos funcionais são todos os alimentos ou bebidas que, consumidos na alimentação cotidiana, podem trazer benefícios fisiológicos específicos, graças à presença de ingredientes fisiologicamente saudáveis (CÂNDIDO \& CAMPOS, 2005).

O termo nutracêutico define uma ampla variedade de alimentos e componentes alimentícios com apelos médico ou de saúde. Sua ação varia do suprimento de minerais e vitaminas essenciais até a proteção contra várias doenças infecciosas (HUNGENHOLTZ \& SMID, 2002). Tais produtos podem abranger nutrientes isolados, suplementos dietéticos e dietas para alimentos geneticamente planejados, alimentos funcionais, produtos herbais e alimentos processados tais como cereais, sopas e bebidas (KWAK \& JUKES, 2001a).

A diferenciação entre alimentos funcionais e nutracêuticos justifica-se devido ao pouco conhecimento destes conceitos pela população, bem como da relação entre dieta e saúde. Dispondo de maiores informações, tanto sobre o efeito benéfico de determinados alimentos, como os maléficos causados pela exposição a inúmeras substâncias inerentes à vida moderna, as pessoas poderão conferir maior importância aos alimentos, contendo substâncias benéficas à saúde. A informação contribui para uma maior aceitação dos alimentos funcionais, diferenciando-os dos nutracêuticos, os quais envolvem todos os tipos de alimentos que possuem algum efeito médico e de saúde.

Diante do exposto, objetiva-se definir e comparar os alimentos funcionais e nutracêuticos, apresentando os principais grupos de compostos funcionais e seus benefícios à saúde.

\section{Alimentos funcionais e Nutracêuticos: definições}

Um alimento pode ser considerado funcional se for demonstrado que o mesmo pode afetar beneficamente uma ou mais funções alvo no corpo, além de possuir os adequados efeitos nutricionais, de maneira que seja tanto relevante para o bem-estar e a saúde quanto para a redução do risco de uma doença (ROBERFROID, 2002). Os alimentos funcionais são alimentos que provêm a oportunidade de combinar produtos comestíveis de alta flexibilidade com moléculas biologicamente ativas, como estratégia para consistentemente corrigir distúrbios metabólicos (WALZEM, 2004), resultando em redução dos riscos de doenças e manutenção da saúde (ANJO, 2004).

Os alimentos funcionais se caracterizam por oferecer vários benefícios à saúde, além do valor nutritivo inerente à sua composição química, podendo desempenhar um papel potencialmente benéfico na redução do risco de doenças crônico degenerativas (NEUMANN, et al., 2000; TAIPINA, et al., 2002).

Os alimentos e ingredientes funcionais podem ser classificados de dois modos: quanto à fonte, de origem vegetal ou animal, ou quanto aos benefícios que oferecem, atuando em seis áreas do organismo: no sistema gastrointestinal; no sistema cardiovascular; no metabolismo de substratos; no crescimento, no desenvolvimento e diferenciação celular; no comportamento das funções fisiológicas e como antioxidantes (SOUZA, et al., 2003).

Uma grande variedade de produtos tem sido caracterizada como alimentos funcionais, incluindo componentes que podem afetar inúmeras funções corpóreas, relevantes tanto para o estado de bem-estar e saúde como para a redução do risco de doenças. Esta classe de compostos pertence à nutrição e não à farmacologia, merecendo uma categoria própria, que não inclua suplementos alimentares, mas o seu papel em relação às doenças estará, na maioria dos casos, concentrado mais na redução dos riscos do que na prevenção.

Os alimentos funcionais apresentam as seguintes características:

a) devem ser alimentos convencionais e serem consumidos na dieta normal/usual;

b) devem ser compostos por componentes naturais, algumas vezes, em elevada concentração ou presentes em alimentos que normalmente não os supririam;

c) devem ter efeitos positivos além do valor básico nutritivo, que pode aumentar o bem-estar e a saúde e/ou reduzir o risco de ocorrência de doenças, promovendo benefícios à saúde além de aumentar a qualidade de vida, incluindo os desempenhos físico, psicológico e comportamental;

d) a alegação da propriedade funcional deve ter embasamento científico; 
e) pode ser um alimento natural ou um alimento no qual um componente tenha sido removido;

g) pode ser um alimento onde a natureza de um ou mais componentes tenha sido modificada;

h) pode ser um alimento no qual a bioatividade de um ou mais componentes tenha sido modificada (ROBERFROID, 2002).

Por sua vez, o nutracêutico é um alimento ou parte de um alimento que proporciona benefícios médicos e de saúde, incluindo a prevenção e/ou tratamento da doença. Tais produtos podem abranger desde os nutrientes isolados, suplementos dietéticos na forma de cápsulas e dietas até os produtos beneficamente projetados, produtos herbais e alimentos processados tais como cereais, sopas e bebidas (KWAK \& JUKES, 2001a; ROBERFROID, 2002; HUNGENHOLTZ, 2002; ANDLAUER \& FÜRST, 2002). Vários nutracêuticos podem ser produzidos através de métodos fermentativos com o uso de microrganismos considerados como GRAS (Generally Recognized as Safe). Os nutracêuticos podem ser classificados como fibras dietéticas, ácidos graxos poliinsaturados, proteínas, peptídios, aminoácidos ou cetoácidos, minerais, vitaminas antioxidantes e outros antioxidantes (glutationa, selênio) (ANDLAUER \& FÜRST, 2002).

O alvo dos nutracêuticos é significativamente diferente dos alimentos funcionais, por várias razões:

a) enquanto que a prevenção e o tratamento de doenças (apelo médico) são relevantes aos nutracêuticos, apenas a redução do risco da doença, e não a prevenção e tratamento da doença estão envolvidos com os alimentos funcionais;

b) enquanto que os nutracêuticos incluem suplementos dietéticos e outros tipos de alimentos, os alimentos funcionais devem estar na forma de um alimento comum (KWAK \& JUKES, 2001b).

Kruger \& Mann (2003) definem os ingredientes funcionais como um grupo de compostos que apresentam benefícios à saúde, tais como as alicinas presentes no alho, os carotenóides e flavonóides encontrados em frutas e vegetais, os glucosinolatos encontrados nos vegetais crucíferos os ácidos graxos poliinsaturados presentes em óleos vegetais e óleo de peixe. Estes ingredientes podem ser consumidos juntamente com os alimentos dos quais são provenientes, sendo estes alimentos considerados alimentos funcionais, ou individualmente, como nutracêuticos. Devem ter adequado perfil de segurança, demonstrando a segurança para o consumo humano. Não devem apresentam risco de toxicidade ou efeitos adversos de drogas medicinais (BAGCHI, et al., 2004).

\section{LEGISLAÇÃO}

O termo "alimentos funcionais" foi primeiramente introduzido no Japão em meados dos anos 80 e se refere aos alimentos processados, contendo ingredientes que auxiliam funções específicas do corpo além de serem nutritivos, sendo estes alimentos definidos como "Alimentos para uso específico de saúde" (Foods for Specified Health Use-FOSHU) em 1991. Estabelece-se que FOSHU são aqueles alimentos que têm efeito específico sobre a saúde devido a sua constituição química e que não devem expor ao risco de saúde ou higiênico.

No Reino Unido, o Ministério da Agricultura, Pesca e Alimentos (MAFF) define alimentos funcionais como "um alimento cujo componente incorporado oferece benefício fisiológico e não apenas nutricional". Esta definição ajuda distinguir alimentos funcionais de alimentos fortificados com vitaminas e minerais.

Nos Estados Unidos da América do Norte os termos alimentos funcionais e nutracêuticos têm sido usados conforme a definição estabelecida. No entanto, a dificuldade se encontra na regulamentação destes termos, pois deve haver uma diferenciação entre produtos que são vendidos e consumidos como alimentos (funcionais) e aqueles que um componente, em particular, foi isolado e é vendido na forma de barras, cápsulas, pós, entre outros (nutracêuticos). A separação desses produtos é necessária quando se estabelece limites de consumo (PIMENTEL, et al., 2005).

O Comitê de Alimentos e Nutrição do Instituto de Medicina da FNB (Federação Náutica de Brasília) define alimentos funcionais como qualquer alimento ou ingrediente que possa proporcionar um benefício à saúde, além dos nutrientes tradicionais que eles contêm (HASLER, 1998).

O escritório Americano de Contas Gerais (US General Accounting Office-GAO) define alimentos funcionais como alimentos que se declaram ter benefícios além da nutrição básica. Entretanto, em matéria de lei, um alimento funcional não tem nenhuma definição reconhecida pela FDC (Food, Drugs and Cosmetics). A FDA (Food and Drug Administration) regula os alimentos funcionais, baseada no uso que se pretende dar ao produto, na descrição presente nos rótulos ou nos ingredientes do produto. A partir destes critérios, a FDA classificou os alimentos funcionais em cinco categorias: alimento, suplementos alimentares, alimento para usos dietéticos especiais, alimento-medicamento ou droga (NOONAN \& NOONAN, 2004).

O alimento é definido como artigos usados para comer e beber por homens ou outros animais e goma de mascar, assim como os artigos usados para compor qualquer artigo do tipo. Um alimento é algo que possa ser consumido pelo seu gosto, aroma ou valor nutritivo. A FDA define valor nutritivo como aquele que sustenta a existência humana de tal maneira que promova crescimento, substituição de nutrição essencial perdida, ou proveja energia (NOONAN \& NOONAN, 2004). Para o Codex Alimentarius, alimento é definido como sendo qualquer substância, quer seja processada, semi-processada ou crua, destinada ao consumo humano, incluindo bebidas, goma de mascar e qualquer substância que seja usada na fabricação, preparação ou tratamento do alimento. Porém, não inclui cosméticos, tabaco ou substâncias usadas apenas como drogas (SOUZA, et al., 2003). 
A definição de que o alimento funcional pode ser classificado como alimento é aceita nos EUA, Europa e também no Brasil. Nessa perspectiva, o alimento funcional deve apresentar primeiramente as funções nutricional e sensorial, sendo a funcionalidade a função terciária do alimento (KWAK \& JUKES, 2001a).

Os suplementos alimentares são produtos alimentícios feitos com o propósito de serem ingeridos na forma de tabletes, farinha, géis, cápsulas de gel ou gotas líquidas e que forneçam vitaminas, minerais, ervas ou outro substrato botânico, aminoácidos ou outra substância dietética (incluindo um concentrado metabólico, componente, extrato ou combinação de qualquer um dos referidos acima) (NOONAN \& NOONAN, 2004; KWAK \& JUKES, 2001b). Nos EUA, os suplementos dietéticos são considerados alimentos funcionais já que segundo a legislação deste país, um alimento funcional pode ser definido como qualquer alimento ou ingrediente que traga algum benefício à saúde além da função nutricional básica (KWAK \& JUKES, 2001a). Entretanto, as definições de suplementos alimentares e alimentos funcionais diferem nas legislações do Japão e da União Européia, por considerarem que um ingrediente de um alimento, por si só, não possa ser considerado um alimento funcional, uma vez que pode chegar ao consumidor na mesma forma de venda que as drogas, ou seja, na forma de tabletes ou similares. Por este motivo, os alimentos funcionais se distinguem claramente dos suplementos alimentares ou dietéticos, visto que a premissa básica de um alimento funcional é que este deve ser consumido como parte de uma dieta na forma de um alimento convencional (KWAK \& JUKES, 2001a; KWAK \& JUKES, 2001b).

Os alimentos para fins dietéticos especiais são aqueles processados ou formulados para atender as necessidades de grupos específicos da população, devido a uma determinada condição fisiológica. Podem ser usados em grupos como lactentes, gestantes, idosos, em pessoas com necessidade de controle de peso, pessoas com hipersensibilidade a determinados componentes dos alimentos, dentre outros. Os alimentos para fins dietéticos especiais podem ser alimentos funcionais desde que sejam apresentados sob a forma de um alimento convencional e não apresentem a alegação de prevenção ou tratamento de uma doença em particular (NOONAN \& NOONAN, 2004; KWAK \& JUKES, 2001b).

Os alimentos medicamentos são definidos pela FDC como sendo alimentos formulados para serem consumidos sob a supervisão de um médico. Estes alimentos são usados para fins dietéticos específicos em caso de doença ou condição para qual existam requisitos nutricionais distintos. Estes requisitos devem ser baseados em princípios científicos conhecidos e que sejam estabelecidos por avaliação médica (NOONAN \& NOONAN, 2004). De acordo com o Codex Alimentarius, alimentos para fins médicos especiais são definidos como uma categoria de alimentos para usos dietéticos especiais, que são especialmente processados ou formulados e apresentados para o controle dietético de pacientes, podendo ser usados somente sob supervisão médica. Nos EUA, o termo alimento-medicamento é legalmente definido como: "um alimento que é formulado para ser administrado inteiramente sob a supervisão de um médico e que é utilizado para o controle de uma doença ou condição para os quais possui requerimentos nutricionais distintos, baseado em princípios científicos reconhecidos". De acordo a FDA, a diferença entre alimentos-medicamentos e alimentos para fins dietéticos especiais é que os primeiros incluem-se em uma categoria mais estreita de alimentos, usados por pessoas com doenças ou condições particulares, as quais possuem requerimentos nutricionais distintos. Os alimentos para fins dietéticos especiais pertencem a uma categoria mais ampla de alimentos, usados por pessoas com necessidades ou desejos por dietas especiais. Desta forma, como os alimentos-medicamentos necessitam de supervisão médica, não podem ser incluídos na categoria de alimentos funcionais (KWAK \& JUKES, 2001b).

Finalmente, em relação às drogas, muitas indústrias, intencionalmente, não comercializam produtos como alimentos funcionais com a intenção de que sejam classificados como drogas. Esta é freqüentemente a armadilha para declarações agressivas ou inclusão dos novos ingredientes não aprovados para serem comercializados. Produtos atualmente nas prateleiras de varejos exemplificam que muitas indústrias de alimentos funcionais ignoram os princípios legais da FDA (NOONAN \& NOONAN, 2004). Nos países ocidentais existe uma distinção clara entre alimentos e drogas, que tem sido incorporada em seu sistema de regulamentação. Essa tendência também ocorre em muitos países orientais, onde muitas partes de seus sistemas de regulamentação têm sido importadas dos países ocidentais, com poucas exceções. Os alimentos funcionais podem, entretanto, desafiar a clara distinção entre alimento e droga, o que pode levar a confusão. Portanto, é importante rever a relação entre alimentos e drogas para tornar clara a finalidade dos alimentos funcionais.

No Brasil, o Ministério da Saúde, através da Agência Nacional de Vigilância Sanitária (ANVISA), regulamentou os Alimentos Funcionais através das seguintes resoluções: ANVISA/MS 16/99; ANVISA/MS 17/99; ANVISA/MS 19/99, cuja essência é:

a) Resolução da ANVISA/MS 16/99 - trata de Procedimentos para Registro de Alimentos e ou Novos Ingredientes, cuja característica é de não necessitar de um Padrão de Identidade e Qualidade (PIQ) para registrar um alimento, além de permitir o registro de novos produtos sem histórico de consumo no país e também novas formas de comercialização para produtos já consumidos (BRASIL, 1999a);

b) Resolução da ANVISA/MS 17/99 - Aprova o Regulamento Técnico que estabelece as Diretrizes Básicas para Avaliação de Risco e Segurança de Alimentos que prova, baseado em estudos e evidências científicas, se o produto é seguro sob o ponto de risco à saúde ou não (BRASIL, 1999b);

c) Resolução ANVISA/MS 18/99 - Aprova o Regulamento Técnico que estabelece as Diretrizes Básicas para a Análise e Comprovação de Propriedades Funcionais e/ou de Saúde, alegadas em rotulagem de alimentos (BRASIL, 1999c); 
d) Resolução ANVISA/MS 19/99 - Aprova o Regulamento Técnico de Procedimentos para Registro de Alimentos com Alegação de Propriedades Funcionais e ou de Saúde em sua Rotulagem (BRASIL, 1999d).

As diretrizes para a utilização da alegação de propriedades funcionais e ou de saúde, segundo a ANVISA são:

a) A alegação de propriedades funcionais e ou de saúde é permitida em caráter opcional;

b) O alimento ou ingrediente que alegar propriedades funcionais ou de saúde pode, além de funções nutricionais básicas, quando se tratar de nutriente, produzirem efeitos metabólicos e ou fisiológicos e ou efeitos benéficos à saúde, devendo ser seguro para consumo sem supervisão médica;

c) São permitidas alegações de função ou conteúdo para nutrientes e não nutrientes, podendo ser aceitas aquelas que descrevem o papel fisiológico do nutriente ou não nutriente no crescimento, desenvolvimento e funções normais do organismo, mediante demonstração da eficácia. Para os nutrientes com funções plenamente reconhecidas pela comunidade científica não será necessária a demonstração de eficácia ou análise da mesma para alegação funcional na rotulagem (item 3.3 da Resolução ANVISA n 18);

d) No caso de uma nova propriedade funcional, há necessidade de comprovação científica da alegação de propriedades funcionais e ou de saúde e da segurança de uso, segundo as Diretrizes Básicas para avaliação de Risco e Segurança dos alimentos;

e) as alegações podem fazer referências à manutenção geral da saúde, ao papel fisiológico dos nutrientes e não nutrientes e à redução de risco de doenças. Não são permitidas alegações de saúde que façam referência à cura ou prevenção de doenças (BRASIL, 1999c; BRASIL, 1999d).

O registro de um alimento funcional só pode ser realizado após comprovada a alegação de propriedades funcionais ou de saúde com base no consumo previsto ou recomendado pelo fabricante, na finalidade, condições de uso e valor nutricional, quando for o caso ou na evidência(s) científica(s): composição química ou caracterização molecular, quando for o caso, e ou formulação do produto; ensaios bioquímicos; ensaios nutricionais e ou fisiológicos e ou toxicológicos em animais de experimentação; estudos epidemiológicos; ensaios clínicos; evidências abrangentes da literatura científica, organismos internacionais de saúde e legislação internacionalmente reconhecidas sob propriedades e características do produto e comprovação de uso tradicional, observado na população, sem associação de danos à saúde (Brasil, 1999c; Brasil 1999d; PIMENTEL, et al., 2005).

\section{CLASSES DE COMPOSTOS FUNCIONAIS E NUTRACÊUTICOS}

\subsection{Probióticos e prebióticos}

Os probióticos são microrganismos vivos que podem ser agregados como suplementos na dieta, afetando de forma benéfica o desenvolvimento da flora microbiana no intestino. São também conhecidos como bioterapêuticos, bioprotetores e bioprofiláticos e são utilizados para prevenir as infecções entéricas e gastrointestinais (REIG \& ANESTO, 2002). A definição internacional atualmente aceita é de que os probióticos são microrganismos vivos, administrados em quantidades adequadas, que conferem benefícios à saúde do hospedeiro (SAAD, 2006).

Em um intestino adulto saudável, a microflora predominante se compõe de microrganismos promotores da saúde, em sua maioria pertencente aos gêneros Lactobacillus e Bifidobacterium. Os Lactobaccilus geralmente citados como probióticos são: L. casei, L. acidophilus, L.delbreuckii subsp. bulgaricus, L. brevis, L. cellibiosus, L.lactis, L. fermentum, L. plantarum e L. reuteri. As espécies de Bifidobacteria com atividade probiótica são: $B$. bifidum, B. longum, B. infantis, B. adolescentis, B. thermophilum e B. animalis (KALANTZOPOULOS, 1997). Segundo Holzapfel \& Schillinger (2002), outras bactérias ácido-láticas com propriedades probióticas são: Ent. faecalis, Ent. faecium e Sporolactobacillus inulinus, enquanto os microrganismos Bacillus cereus, Escherichia coli Nissle, Propionibacterium freudenreichii e Saccharomyces cerevisiae têm sido citados como microrganimos não láticos associados à atividades probióticas principalmente para uso farmacêutico ou em animais.

"Os benefícios à saúde do hospedeiro atribuídos à ingestão de culturas probióticas são: controle da microbiota intestinal, estabilização da microbiota intestinal após o uso de antibióticos, promoção da resistência gastrintestinal à colonização por patógenos, diminuição da concentração dos ácidos acético e lático, de bacteriocinas e outros compostos antimicrobianos, promoção da digestão da lactose em indivíduos intolerantes à lactose, estimulação do sistema imune, alívio da constipação e aumento da absorção de minerais e vitaminas" (SAAD, 2006, p.5).

O Quadro 1 relaciona as causas e mecanismos dos efeitos benéficos atribuídos aos probióticos.

Segundo Short (1999), dentre 20 critérios para a seleção de microrganismos probióticos para uso em alimentos, os mais importantes são: serem de origem humana, não serem patogênicos, apresentarem tolerância ao trato gastrointestinal, possuírem habilidade de sobreviver aos processos tecnológicos, permanecerem viáveis durante a vida-de-prateleira e terem os benefícios à saúde comprovados. Já segundo Salminem, et al. (1998), os critérios para a seleção de probióticos dizem respeito ao gênero a que os microrganismos pertencem (origem, definição, caracterização, espécies seguras), a sua estabilidade e segurança (atividade e viabilidade nos produtos, aderência e potencial invasivo, bem como resistência ao baixo $\mathrm{pH}$, aos sucos gástrico, biliar e pancreático, à 
capacidade de colonização) e aos aspectos funcionais e fisiológicos (aderência ao epitélio intestinal, antagonismo aos patógenos, estimulação ou supressão da resposta imunológica, estimulação às bactérias benéficas).

Quadro 1. Causas e mecanismos dos efeitos benéficos atribuídos aos probióticos

\begin{tabular}{|c|c|}
\hline Efeito benéfico & Possíveis causas e mecanismos \\
\hline Melhor digestibilidade & Degradação parcial das proteínas, lipídios e carboidratos \\
\hline Melhor valor nutritivo & $\begin{array}{l}\text { Níveis elevados das vitaminas do complexo B e de alguns aminoácidos } \\
\text { essenciais como metionina, lisina e triptofano }\end{array}$ \\
\hline Melhor utilização da lactose & Níveis reduzidos de lactose no produto e maior disponibilidade de lactase \\
\hline $\begin{array}{l}\text { Ação antagônica contra agentes } \\
\text { patogênicos entéricos }\end{array}$ & $\begin{array}{l}\text { Distúrbios tais como diarréia, colites mucosa e ulcerosa, diverticulite e colite } \\
\text { antibiótica são controlados pela acidez } \\
\text { Inibidores microbianos e inibição da adesão e ativação de patógenos }\end{array}$ \\
\hline Colonização do intestino & $\begin{array}{l}\text { Sobrevivência ao ácido gástrico, resistência a lisozima e à tensão superficial } \\
\text { do intestino, adesão ao epitélio intestinal, multiplicação no trato } \\
\text { gastrointestinal, modulação imunitária }\end{array}$ \\
\hline Ação anticarcinogênica & $\begin{array}{l}\text { Conversão de potenciais pré-carcinogênicos em compostos menos } \\
\text { perniciosos } \\
\text { Estimulação do sistema imunitário }\end{array}$ \\
\hline Ação hipocolesterolêmica & $\begin{array}{l}\text { Produção de inibidores da síntese do colesterol } \\
\text { Utilização do colesterol por assimilação e precipitação como sais biliares } \\
\text { desconjugados }\end{array}$ \\
\hline Modulação imunitária & $\begin{array}{l}\text { Melhor produção de macrófagos, estimulação da produção de células } \\
\text { supressoras }\end{array}$ \\
\hline
\end{tabular}

Fonte: KAUR, et al., 2002; HOLZAPFEL \& SCHILLINGER, 2002; KALANTZOPOULOS, 1997.

Os prebióticos são oligossacarídeos não digeríveis, porém fermentáveis cuja função é mudar a atividade e a composição da microbiota intestinal com a perspectiva de promover a saúde do hospedeiro. As fibras dietéticas e os oligossacarídeos não digeríveis são os principais substratos de crescimento dos microrganismos dos intestinos. Os prebióticos estimulam o crescimento dos grupos endógenos de população microbiana, tais como as Bifidobactérias e os Lactobacillos, que são ditos como benéficos para a saúde humana (BLAUT, 2002). Os prebióticos mais eficientes irão reduzir a atividade de organismos potencialmente patogênicos (ROBERFROID, 2002). Para que uma substância (ou grupo de substâncias) possa ser definida como tal, deve cumprir os seguintes requisitos: ser de origem vegetal; formar parte de um conjunto heterogêneo de moléculas complexas; não ser digerida por enzimas digestivas; ser parcialmente fermentada por uma colônia de bactérias e ser osmoticamente ativa (RODRÍGUEZ, et al., 2003). Por exemplo, alguns oligossacarídeos como a oligofrutose e a inulina, conduzem a um aumento significativo do número de bifidobactérias.

"Um produto em que estão combinados um probiótico e um prebiótico é denominado simbiótico. A interação entre o probiótico e o prebiótico in vivo pode ser favorecida por uma adaptação do probiótico ao substrato prebiótico anterior ao consumo. Isto pode, em alguns casos, resultar em uma vantagem competitiva para 0 probiótico, se ele for consumido juntamente com o prebiótico" (SAAD, 2006, p. 3).

Alguns efeitos atribuídos aos prebióticos são: a modulação de funções fisiológicas chaves, como a absorção de cálcio, o metabolismo lipídico, a modulação da composição da microbiota intestinal, a qual exerce um papel primordial na fisiologia intestinal e a redução do risco de câncer de cólon (ROBERFROID, 2002).

Os iogurtes e leites fermentados são os alimentos mais comuns a serem suplementados com probióticos. Os leites não fermentados, sucos e outros alimentos também podem ser suplementados com probióticos (SOUZA, et al., 2003).

\subsection{Alimentos sulfurados e nitrogenados}

Os alimentos sulfurados e nitrogenados são compostos orgânicos usados na proteção contra a carcinogênese e mutagênese, sendo ativadores de enzimas na detoxificação do fígado (ANJO, 2004). As propriedades anticarcinogênicas dos vegetais crucíferos como repolho, brócolis, rabanete, palmito e alcaparra são atribuídas ao seu conteúdo relativamente alto de glicosilatos (HASLER, 1998).

Os isotiacianatos e indóis são compostos antioxidantes que estão presentes em crucíferas, tais como brócolis, couve-flor, couve-de-bruxelas, couve e repolho. Esses compostos inibem a mutação do DNA, que predispõe algumas formas de câncer (SOUZA, et al., 2003).

\subsection{Vitaminas antioxidantes}


"A oxidação nos sistemas biológicos ocorre devido à ação dos radicais livres no organismo. Estas moléculas têm um elétron isolado, livre para se ligar a qualquer outro elétron, e por isso são extremamente reativas. Elas podem ser geradas por fontes endógenas ou exógenas. Por fontes endógenas, originam-se de processos biológicos que normalmente ocorrem no organismo, tais como: redução de flavinas e tióis; resultado da atividade de oxidases, cicloxigenases, lipoxigenases, desidrogenases e peroxidases; presença de metais de transição no interior da célula e de sistemas de transporte de elétrons. Esta geração de radicais livres envolve várias organelas celulares, como mitocôndrias, lisossomos, peroxissomos, núcleo, retículo endoplasmático e membranas. As fontes exógenas geradoras de radicais livres incluem tabaco, poluição do ar, solventes orgânicos, anestésicos, pesticidas e radiações" (SOARES, 2002).

"As lesões causadas pelos radicais livres nas células podem ser prevenidas ou reduzidas por meio da atividade de antioxidantes, sendo estes encontrados em muitos alimentos. Os antioxidantes podem agir diretamente na neutralização da ação dos radicais livres ou participar indiretamente de sistemas enzimáticos com essa função. Dentre os antioxidantes estão a vitamina $C$, a glutationa, o ácido úrico, a vitamina $E$ e os carotenóides" (SHAMI \& MOREIRA, 2004).

Os carotenóides estão presentes em alimentos com pigmentação amarela, laranja ou vermelha (tomate, abóbora, pimentão, laranja). Seus principais representantes são os carotenos, precursores da vitamina $\mathrm{A}$ e o licopeno (GAZZONI, 2003). As xantofilas são sintetizadas a partir dos carotenos, por meio de reações de hidroxilação e epoxidação. O $\beta$-caroteno e o licopeno são exemplos de carotenos, enquanto a luteína e a zeaxantina são xantofilas. Dos mais de 600 carotenóides conhecidos, aproximadamente 50 são precursores da vitamina $A$. $O$ carotenóide precursor possui pelo menos um anel de $\beta$-ionona não substituído, com cadeia lateral poliênica com um mínimo de 11 carbonos. Entre os carotenóides, o $\beta$-caroteno é o mais abundante em alimentos e o que apresenta a maior atividade de vitamina $A$. Tanto os carotenóides precursores de vitamina $A$ como os não precursores, como a luteína, a zeaxantina e o licopeno, parecem apresentar ação protetora contra o câncer, sendo que os possíveis mecanismos de proteção são por intermédio do seqüestro de radicais livres, modulação do metabolismo do carcinoma, inibição da proliferação celular, aumento da diferenciação celular via retinóides, estimulação da comunicação entre as células e aumento da resposta imune. $O \quad \beta$-caroteno é um potente antioxidante com ação protetora contra doenças cardiovasculares. A oxidação do LDL (low density lipoprotein) é fator crucial para o desenvolvimento da aterosclerose e o $\beta$-caroteno atua inibindo o processo de oxidação da lipoproteína. Estudos apontam que a luteína e a zeaxantina, que são amplamente encontradas em vegetais verdeescuros, parecem exercer uma ação protetora contra degeneração macular e catarata (AMBRÓSIO, et al., 2006).

Segundo Stahl \& Sies (2003) os carotenóides fazem parte do sistema de defesa antioxidante em humanos e animais. Devido à sua estrutura atuam protegendo as estruturas lipídicas da oxidação ou por seqüestro de radicais livres gerados no processo foto-oxidativo. A Figura 1 apresenta estruturas de carotenóides.
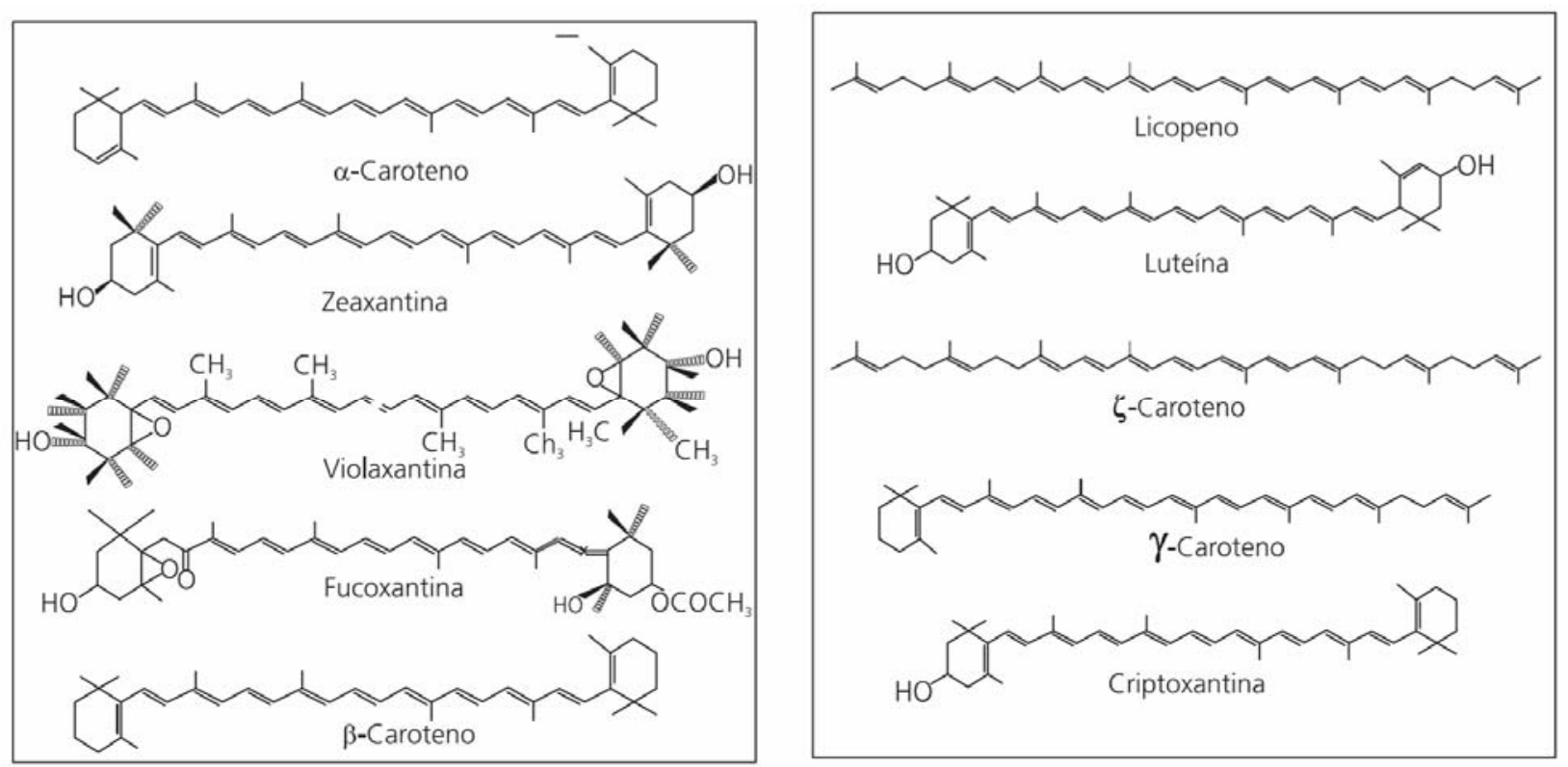

Figura 1. Estruturas químicas de carotenóides Fonte: AMBRÓSIO et al.(2006)

A vitamina $E$ é a principal vitamina antioxidante transportada na corrente sangüínea pela fase lipídica das partículas lipoprotéicas. Junto com o beta-caroteno e outros antioxidantes naturais, chamados ubiquinonas, a vitamina $E$ protege os lipídios da peroxidação. A ingestão de vitamina $E$ em quantidades acima das recomendações correntes pode reduzir o risco de doenças cardiovasculares, melhorar a condição imune e modular condições degenerativas importantes associadas com envelhecimento (SOUZA, et al., 2003). 
"A vitamina E é um componente dos óleos vegetais encontrada na natureza em quatro formas diferentes $\alpha$, $\beta, \gamma$ e $\delta$-tocoferol, sendo o $\alpha$-tocoferol a forma antioxidante amplamente distribuída nos tecidos e no plasma. A vitamina $E$ encontra-se em grande quantidade nos lipídeos, e evidências recentes sugerem que essa vitamina impede ou minimiza os danos provocados pelos radicais livres associados com doenças específicas, incluindo o câncer, artrite, catarata e o envelhecimento. A vitamina $E$ tem a capacidade de impedir a propagação das reações em cadeia induzidas pelos radicais livres nas membranas biológicas. Os danos oxidativos podem ser inibidos pela ação antioxidante dessa vitamina, juntamente com a glutationa, a vitamina $\mathrm{C}$ e os carotenóides, constituindo um dos principais mecanismos da defesa endógena do organismo" (BIANCHI \& ANTUNES, 1999).

A Figura 2 apresenta a estrutura química de tocoferóis.

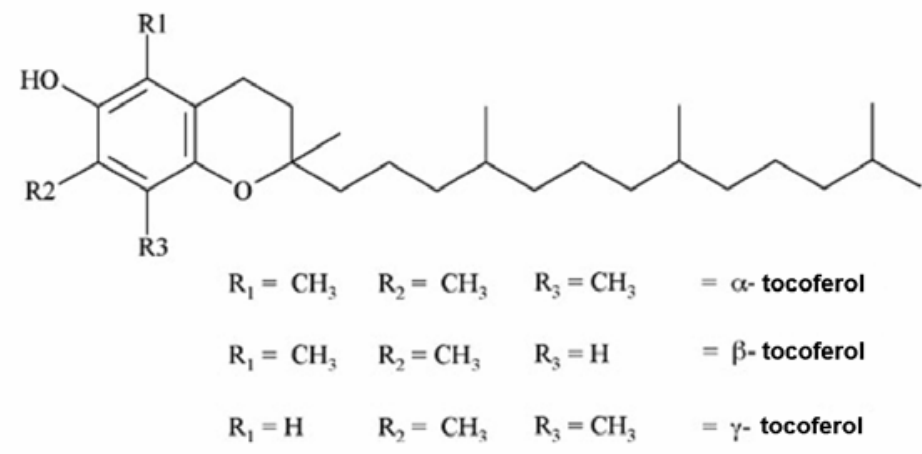

Figura 2. Estrutura química de tocoferóis Fonte: SPEER \& SPEER (1999).

A vitamina C (ácido ascórbico) é, geralmente, consumida em grandes doses pelos seres humanos, sendo adicionada a muitos produtos alimentares para inibir a formação de metabólitos nitrosos carcinogênicos. Os benefícios obtidos na utilização terapêutica da vitamina $\mathrm{C}$ em ensaios biológicos com animais incluem o efeito protetor contra os danos causados pela exposição às radiações e medicamentos. Os estudos epidemiológicos também atribuem a essa vitamina um possível papel de proteção no desenvolvimento de tumores nos seres humanos. Contudo, a recomendação de suplementação dessa vitamina deve ser avaliada especificamente para cada caso, pois existem muitos componentes orgânicos e inorgânicos nas células que podem modular a atividade da vitamina C, afetando sua ação antioxidante (BIANCHI \& ANTUNES, 1999). A Figura 3 apresenta a estrutura química da vitamina $\mathrm{C}$.

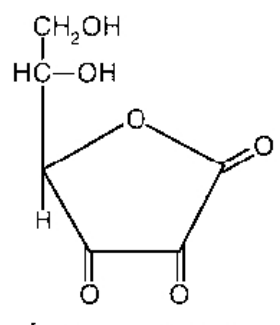

Ácido ascórbico

Figura 3 Estrutura da vitamina C.

\subsection{Compostos Fenólicos}

Os flavonóides compõem uma ampla classe de substâncias de origem natural, cuja síntese não ocorre na espécie humana. Entretanto, tais compostos possuem uma série de propriedades farmacológicas que os fazem atuarem sobre os sistemas biológicos (LOPES, et al., 2003), por exemplo, como antioxidantes. A dieta mediterrânea, rica em frutas frescas e vegetais, tem sido associada com a baixa incidência de doenças cardiovasculares e câncer, principalmente devido à elevada proporção de compostos bioativos como vitaminas, flavonóides e polifenóis (BENAVENTE-GARCÍA, et al., 1999). Ainda há o conhecido "paradoxo francês", uma aparente compatibilidade de uma dieta com alta ingestão de gordura e com uma baixa incidência de coronariopatia ateroesclerótica, atribuído à presença de compostos fenólicos no vinho tinto, com propriedades antioxidantes que inibem a oxidação das LDLs, evitando indiretamente os infiltrados de lipídios no interior das artérias (AMARAL, et al., 1995).

Os flavonóides englobam uma classe importante de pigmentos naturais encontrados com freqüência na natureza, unicamente em vegetais. As substâncias fenólicas se caracterizam por possuir um grupo funcional oxidrílico $(\mathrm{OH})$ ligado a um anel benzênico. Os compostos fenólicos são inumeráveis e a partir da molécula 
simples de fenol podem se derivar substâncias com diferentes níveis de complexidade, que podem ser classificadas em várias famílias e grupos. Naturalmente, nem todas estas substâncias são isoláveis ou identificáveis nos tecidos vegetais. São vários os critérios disponíveis para classificação de compostos fenólicos, porém a forma mais simples, didática e a mais utilizada são: fenóis simples, fenóis compostos e os flavonóides, que se constituem na família mais vasta de compostos fenólicos naturais e estão amplamente distribuidos nos tecidos vegetais. Eles são solúveis em água e em solventes polares, principalmente álcoois. Quimicamente contem dois anéis benzênicos com pontes de 3 carbonos condensadas num oxigênio formando um anel intermediário (C6-C3-C6). Os verdadeiros flavonóides são as antocianinas (pigmentos azul-púrpura), as antoxantinas (amarelas), as catequinas e as leucoantocianinas que são incolores, mas que facilmente se tranformam em pigmentos pardos. Estas duas últimas são comumente denonimadas taninos. As antoxantinas e flavonas são derivadas do fenil-2-benzopiranos e aparecem dissolvidos nas células de vegetais. Usualmente são amarelos claros ou incolores estando presentes em polpas de frutas claras ou aquelas coloridas de verde com clorofila ou vermelho, azul ou púrpura com antocianinas (RIBEIRO \& SERAVALLI, 2004).

O potencial antioxidante de um composto é determinado pela reatividade dele como um doador de elétrons ou hidrogênio, capacidade de deslocar ou estabilizar um elétron desemparelhado, reatividade com outro antioxidante e reatividade com oxigênio molecular. Outros efeitos fisiológicos da ação de compostos antioxidantes seriam sua atuação como anticancerígenos e antimutagênicos sempre considerando que estes problemas ocorram por ação de radicais livres.

A formação de radicais livres está associada com o metabolismo normal de células aeróbicas. O consumo de oxigênio inerente à multiplicação celular leva a geração de uma série de radicais livres. A interação destas espécies com moléculas de natureza lipídica em excesso produz novos radicais: hidroperóxidos e diferentes peróxidos. Estes grupos de radicais podem interagir com os sistemas biológicos de formas citotóxicas. Com respeito a isto, flavonóides e fenóis têm sido reportados por possuírem atividade antioxidante contra os radicais livres, a qual está associada às propriedades redox dos grupos hidroxil e a sua relação com diferentes partes da estrutura química (BENAVENTE-GARCÍA, et al., 1999).

Esta capacidade de inativar radicais livres dos flavonóides em meio aquoso e lipofílico vem sendo amplamente estudada in vitro. Os estudos empregam como formadores de espécies oxigeno-reativas a luz UV, radiações, sistema hipoxantina-xantina oxidase ou íons metálicos e como substratos, os lipídios, usualmente contidos em homogeneizados de tecidos, lipossomas, micelas ou sistemas lipídicos como metil linoleato ou lipoproteínas de baixa densidade e tecidos animais (BADIALE-FURLONG, et al., 1996). As substâncias fenólicas empregadas nestes estudos são extraídas de vários tipos de tecidos vegetais com sistemas aquosos e submetidas à avaliação de atividade antioxidante in vivo e in vitro. A motivação para tais estudos é a vantagem deste efeito minimizar o desenvolvimento ou os sintomas de doenças crônicas, tais como aterosclerose e distúrbios do metabolismo de lipídios.

"Antioxidantes fenólicos funcionam como seqüestradores de radicais e algumas vezes como quelantes de metais agindo tanto na etapa de iniciação como na propagação do processo oxidativo. Os produtos intermediários, formados pela ação destes antioxidantes, são relativamente estáveis devido à ressonância do anel aromático apresentada por estas substâncias" (SOARES, 2002).

Uma subclasse dos flavonóides são as isoflavonas (ANJO, 2004), as quais têm sido um componente da dieta de certas populações durante muitos séculos. O consumo da soja tem sido considerado benéfico, com um efeito potencialmente protetor contra um número de doenças crônicas (MUNRO, 2003). Não houve indicação de risco à saúde por causa do consumo de soja ou isoflavonas da soja como parte regular da dieta; ao contrário, os estudos epidemiológicos das últimas décadas sugeriram efeitos protetores destes compostos contra um número de doenças crônicas, incluindo doença cardíaca coronária, câncer de próstata, diabetes, osteoporose, deficiência cognitiva, doenças cardiovasculares e efeitos da menopausa. Apresenta estrutura e atividade semelhante ao estrógeno humano e são conhecidas como fitoestrógenos, podendo proteger o organismo contra doenças do coração e possivelmente contra câncer de mama pela ação de estrógenos bloqueadores. Nas culturas orientais, a soja é considerada tanto como um alimento nutritivo quanto como um agente medicinal (ANJO, 2004). Pesquisas recentes têm mostrado que dietas ricas em soja ajudam a reduzir os níveis de colesterol (LDL) no sangue, de 12 a $15 \%$, pois as isoflavonas da soja são convertidas, no intestino, a fitoestrógenos que podem ajudar a reduzir o LDL (SOUZA, et al., 2003).

As isoflavonas são encontradas em legumes, principalmente em grãos de soja. Embora haja uma grande variabilidade de composição de isoflavonas entre os grãos de soja e produtos alimentícios baseados em soja, a maioria das fontes dietéticas contém uma mistura de derivados, baseados em três isoflavonas agliconas: genisteína, daidzeína e gliciteína (PIMENTEL, et al., 2005).

\section{5. Ácidos graxos poliinsaturados}

Os ácidos graxos poliinsaturados, destacando as séries ômega 3 e 6, são encontrados em peixes de água fria (salmão, atum, sardinha, bacalhau), óleos vegetais, sementes de linhaça, nozes e alguns tipos de vegetais. Um ácido graxo é chamado de ômega 3 quando a primeira dupla ligação está localizada no carbono 3 a partir do radical metil $(\mathrm{CH} 3)$, e ômega 6 quando a dupla ligação está no sexto carbono da cadeia a partir do mesmo radical. 
Os principais ácidos graxos da família ômega 3 são o alfa-linolênico (C18:3 - 18 carbonos e 3 insaturações), o eicosapentanóico-EPA (C20:5 - 20 carbonos e 5 insaturações) e o docasahexanóico-DHA (C22:6 - 22 carbonos e 6 insaturações). Os ácidos graxos da família ômega 6 mais importantes são o linoléico (C18:2 dezoito carbono e 2 insaturações) e o araquidônico (C20:4 - 20 carbonos e 4 insaturações) (PIMENTEL, et al., 2005).

Os ácidos graxos de cadeia longa da família ômega 3 (EPA e DHA) são sintetizados nos seres humanos a partir do ácido linolênico. Este ácido graxo é também o precursor primordial das prostaglandinas, leucotrienos e tromboxanos com atividade antiinflamatória, anticoagulante, vasodilatadora e antiagregante (RODRÍGUEZ, et al., 2003; PIMENTEL, et al., 2005). Algas marinhas são capazes de sintetizar os ácidos graxos DHA e EPA, os quais entram na cadeia alimentar marinha. Apesar das controvérsias, o consumo adicional de ácidos graxos ômega 3 (DHA e EPA) na dieta está sendo discutido e recomendada. Estudos epidemiológicos têm demonstrado que a ingestão de peixes regularmente na dieta tem efeito favorável sobre os níveis de triglicerídeos, pressão sanguínea, mecanismo de coagulação e ritmo cardíaco, na prevenção do câncer (mama, próstata e cólon) e redução da incidência de arteriosclerose (SOUZA, et al., 2003). Os ácidos graxos ômega 3 são também indispensáveis para os recém-nascidos por representarem um terço da estrutura de lipídeos no cérebro, carências destas substâncias podem ocasionar redução da produção de enzimas relacionadas às funções do aprendizado. O suprimento adequado de DHA na alimentação dos bebês é fundamental para o desenvolvimento da retina.

Considera-se que os ácidos graxos saturados induzem a hipercolesterolemia enquanto que os ácidos graxos poliinsaturados (PUFA - polyunsaturated fatty acids) apresentam efeito de redução da hipercolesterolemia (LIN HE \& FERNANDEZ, et al., 1998; ERKKILA, et al., 1999; KURUSHIMA, et al., 1995). Há várias explicações acerca dos mecanismos pelos quais os ácidos graxos afetam as concentrações do colesterol plasmático, tais como mudanças na composição das lipoproteínas, na produção de LDL, na produção de VLDL (very low density lipoprotein) pelo fígado e na atividade dos receptores da LDL. No estudo realizado por Kurushima, et al. (1995) os efeitos da adição de colesterol e ácidos graxos na dieta de cobaias hamsters foram avaliados, onde os animais foram alimentados por quatro semanas com dietas padrão adicionadas de colesterol e ácido oléico ou palmítico. A adição de $0,1 \%$ de colesterol à dieta padrão aumentou os níveis plasmáticos de colesterol total, VLDL e LDL. A adição de $5 \%$ de ácido palmítico à dieta com $0,1 \%$ de colesterol aumentou ainda mais os níveis plasmáticos de colesterol total e LDL enquanto que com a adição de $5 \%$ de ácido oléico à dieta com $0,1 \%$ de colesterol houve diminuição dos níveis de colesterol total, VLDL e LDL. Foi atribuída que a ação do ácido oléico deve-se ao aumento da atividade do receptor hepático da LDL, enquanto o ácido palmítico apresentou efeito inverso.

Além de seu papel nutricional na dieta, os ácidos graxos ômega 3 podem ajudar a prevenir ou tratar uma variedade de doenças, incluindo doenças do coração, câncer, artrite, depressão e mal de Alzheimer entre outros. Os ácidos graxos ômega 3 devem ser consumidos numa proporção equilibrada com os ácidos graxos ômega 6 . Nutricionistas acreditam que uma proporção ideal seria de aproximadamente de 5:1 de ômega 6 para ômega 3.

O ácido linoléico, presente no óleo de girassol, pertencente ao grupo dos ácidos graxos ômega 6, é transformado pelo organismo humano no ácido araquidônico e em outros ácidos graxos poliinsaturados. Os ômega 6 derivados do ácido linoléico exercem importante papel fisiológico: participam da estrutura de membranas celulares, influenciando a viscosidade sangüínea, permeabilidade dos vasos, ação antiagregadora, pressão arterial, reação inflamatória e funções plaquetárias. Estudos mostram os efeitos causados pela substituição de gordura saturada por gordura monoinsaturada na dieta, com a redução nos níveis de colesterol total e de LDL, sem alterar significativamente os níveis de HDL (high density lipoprotein). O azeite de oliva é rico em ácido oléico, contendo de 55 a $83 \%$ deste ácido graxo.

\subsection{Fibras (Oligossacarídeos)}

A fibra dietética é uma substância indisponível como fonte de energia, pois não é passível de hidrólise pelas enzimas do intestino humano e que pode ser fermentada por algumas bactérias. A maior parte das substâncias classificadas como fibras são polissacarídios não amiláceos. As fibras são, portanto, substâncias com alto peso molecular, encontradas nos vegetais, tais como os grãos (arroz, soja, trigo, aveia, feijão, ervilha), em verduras (alface, brócoli, couve, couve-flor, repolho), raízes (cenoura, rabanete) e outras hortaliças (chuchu, vagem, pepino) (PIMENTEL, et al., 2005).

Pode-se classificar a fibra segundo o papel que elas cumprem nos vegetais em dois grupos:

a) polissacarídeos estruturais: estão relacionados à estrutura da parede celular e incluem a celulose, as hemiceluloses, pectinas, gomas e mucilagens segregadas pelas células e polissacarídeos tais como o ágar e as carragenas produzidas pelas algas e liquens marinhos;

b) polissacarídeos não estruturais: inclui a lignina (SALINAS, 2002).

Outra classificação possível diferencia as fibras como fibras solúveis e insolúveis. As fibras solúveis são as pectinas e hemiceluloses. Estas tendem a formar géis em contato com água, aumentando a viscosidade dos alimentos parcialmente digeridos no estômago (PIMENTEL, et al., 2005). As fibras solúveis diminuem a absorção de ácidos biliares e têm atividades hipocolesterolêmicas. Quanto ao metabolismo lipídico, parecem diminuir os níveis de triglicerídeos, colesterol e reduzir a insulinemia. Uma característica fundamental da fibra solúvel é sua capacidade para ser metabolizada por bactérias, com a conseguinte produção de gases (flatulência) (RODRÍGUEZ, et al., 2003). 
As fibras insolúveis permanecem intactas através de todo o trato gastrointestinal e compreendem a lignina, a celulose e algumas hemiceluloses (PIMENTEL, et al., 2005). Como funções funcionais da fibra insolúvel estão:

a) o incremento do bolo fecal e o estímulo da motilidade intestinal;

b) a maior necessidade de mastigação, relevantes na sociedade moderna vítimas da ingestão compulsiva e da obesidade;

c) o aumento da excreção de ácidos biliares e propriedades antioxidantes e hipocolesterolêmicas (RODRIGUEZ, et al., 2003).

Segundo Anjo (2004), os efeitos do uso das fibras são a redução dos níveis de colesterol sangüíneo e diminuição dos riscos de desenvolvimento de câncer, decorrentes de três fatores: capacidade de retenção de substâncias tóxicas ingeridas ou produzidas no trato gastrointestinal durante processos digestivos; redução do tempo do trânsito intestinal, promovendo uma rápida eliminação do bolo fecal, com redução do tempo de contato do tecido intestinal com substâncias mutagênicas e carcinogênicas e formação de substâncias protetoras pela fermentação bacteriana dos compostos de alimentação.

\section{CONCLUSÃO}

A partir deste estudo comparativo, realizado acerca dos alimentos funcionais e nutracêuticos, ressalta-se a importância destes compostos no aumento da expectativa de vida da população, uma vez que o crescente aparecimento de doenças crônicas tais como a obesidade, a aterosclerose, a hipertensão, a osteoporose, o diabetes e o câncer têm ocasionado uma preocupação maior, por parte da população e dos órgãos públicos da saúde, com a alimentação.

Nesse contexto, inserem-se os alimentos funcionais, considerados promotores de saúde por estarem associados à diminuição dos riscos de algumas doenças crônicas, uma vez que são encontrados em alimentos naturais ou preparados, contendo uma ou mais substâncias funcionais.

Do ponto de vista legal, constata-se que os alimentos funcionais e nutracêuticos possuem conceituações semelhantes em muitas partes do mundo, concluindo-se que persiste a dificuldade de regulamentação dos termos, pois deve ser mantida a diferença fundamental, que faz com que os alimentos funcionais se relacionem à venda e consumo dos mesmos como alimentos, ao passo que os nutracêuticos são ingredientes funcionais isolados e são consumidos sob diferentes formas, dadas pela indústria farmacêutica.

A esse respeito, o posicionamento profissional dos farmacêuticos, deve se pautar pelas normas legais em nível mundial e nacional, de modo a enfatizar a diferença entre os alimentos que podem ser vendidos sem prescrição médica, daqueles que somente podem ser comercializados com receituário.

Especificamente, em relação aos alimentos funcionais, no Brasil, o farmacêutico deve se ater às orientações da ANVISA, através do que recomendam as Resoluções de números 18 e 19 do ano de 1999, tendo o cuidado de avaliar a segurança dos alimentos em relação aos riscos e à saúde da população em geral.

Dessa forma, este estudo acerca das definições, legislação e benefícios à saúde dos alimentos funcionais e nutracêuticos demonstra que o conhecimento legal e científico, desses aspectos, é decisivo para uma boa atuação do profissional farmacêutico e, certamente, contribuirá na boa orientação às pessoas sobre o benefício proporcionado à fisiologia do organismo, reduzindo os riscos de determinadas doenças, sempre no compasso do avanço das pesquisas, desde que comprovadas e reconhecidas pela comunidade científica, autoridades governamentais e indústrias.

\section{REFERÊNCIAS}

AMARAL, D. M., et al. Efeito inibidor de substâncias antioxidantes existentes no vinho tinto na aterogênese experimental no coelho. Vittalle. v.7, p. 17-24, 1995.

AMBRÓSIO, C. L. B.; CAMPOS, F. A. C. S.; FARO, Z. P. Carotenóides como alternativa contra a hipovitaminose A. Revista de Nutrição. v. 19, n.2, p. 233-243, 2006.

ANDLAUER, W.; FÜRST, P. Nutraceuticals: a piece of history, present status and outlook. Food Research International. v. 35, p. 171-176, 2002.

ANJO, D. L. C. Alimentos funcionais em angiologia e cirurgia vascular. Jornal Vascular Brasileiro. v. 3, n. 2, p. 145154, 2004.

BADIALE FURLONG, E., et al. Boletim do centro de pesquisa e processamento de alimentos. v.14, n.2, p. 273282, 1996.

BAGCHI, D; PREUSS, H. G.; KEHRER, J. A. Nutraceutical and functional food industries: aspects on safety and regulatory requeriments. Toxicology Letters. v.150, p. 1-2, 2004. 
BENAVENTE-GARCIA, O., et al. Antioxidant activity of phenolics extracted from Olea europaea L. leaves. Food Chemistry. v.68, p. 457-462, 1999.

BIANCHI, M. L. P.; ANTUNES, L. M. G. Radicais livres e os principais antioxidantes da dieta. Revista de Nutrição. v. 12, n.2, p. 123-130, 1999.

BLAUT, M. Relationship of prebiotics and food to intestinal microflora. European Journal of Nutrition. v. 41, supplement 1, p.1-16, 2002.

BRASIL. Ministério da Saúde. Agência Nacional de Vigilância Sanitária. Resolução n. 16, de 30 de abril de 1999. Aprova o Regulamento Técnico de Procedimentos para Registro de Alimentos e ou Novos Ingredientes. Brasília, 1999a.

BRASIL. Ministério da Saúde. Agência Nacional de Vigilância Sanitária. Resolução n. 17, de 30 de abril de 1999. Aprova o Regulamento Técnico que Estabelece as Diretrizes Básicas para Avaliação de Risco e Segurança dos Alimentos. Brasília, 1999b.

BRASIL. Ministério da Saúde. Agência Nacional de Vigilância Sanitária. Resolução n. 18, de 30 de abril de 1999. Aprova o Regulamento Técnico que Estabelece as Diretrizes Básicas para Análise e Comprovação de Propriedades Funcionais e ou de Saúde Alegadas em Rotulagem de Alimentos. Brasília, 1999c.

BRASIL. Ministério da Saúde. Agência Nacional de Vigilância Sanitária. Resolução n. 19, de 30 de abril de 1999. Aprova o Regulamento Técnico de Procedimentos para Registro de Alimento com Alegação de Propriedades Funcionais e ou de Saúde em sua Rotulagem. Brasília, 1999d.

CANDIDO, L. M. B.; CAMPOS, A. M. Alimentos funcionais. Uma revisão. Boletim da SBCTA. v. 29, n. 2, p. 193203, 2005.

CHEN, L.; REMONDETTO, E.; SUBIDARE. Food protein-based materials as nutraceutical delivery systems. Trends in Food Science and Technology. n. 17, p. 272-283, 2006.

COOPENS, P.; SILVA, M. F.; PETTMAN, S. European regulations on nutraceuticals, dietary supplements and functional foods: a framework based on safety. Toxicology. v. 221, p. 59-74, 2006.

ERKKILÄ, A. T., et al. Dietary associates of serum total, LDL, and HDL cholesterol and triglycerides in patients with coronary heart disease. Preventive Medicine, v. 28, p. 558-565, 1999.

GAZZONI, D. L. Alimentos funcionais. Embrapa soja, Londrina, maio 2003. Disponível em: Homepage: [capturado em 18 set. 2005].

HASLER, C. M. Functional foods: their role in disease in: developing new food products for a changing prevention and health promotion. Food Technology. v. 52, n. 2. p. 57-62, 1998.

HOLZAPFEL, W. H.; SCHILLINGER, U. Introduction to pre and probiotics. Food Research International. v. 35, p. 109-116, 2002.

HUNGENHOLTZ, J.; SMID, E. J. Nutraceutical production with food-grade microorganisms. Current Opinion in Biotechnology. v. 13, p. 497-507, 2002.

KALANTZOPOULOS, G. Fermented products with probiotic qualities. Anaerobe. v. 3, p. 185-190, 1997.

KAUR, I. P.; CHOPRA, K.; SAINI, A. Probiotics: potencial pharmaceutical applications. European Journal of Pharmaceutical Sciences. v. 15, p. 1-9, 2002.

KRUGER, C. L.; MANN, S. W. Safety evaluation of funcional ingredients. Food and Chemical Toxicology. v. 41, p. 793-805, 2003.

KURUSHIMA, H., et al. Opposite effects on cholesterol metabolism and their mechanisms induced by dietary oleic acid and palmitic acid in hamsters. Biochimica et Biophysica Acta. v. 1258, p. 251-256, 1995.

KWAK, N.; JUKES, D. J. Functional foods. Part 1: the development of a regulatory concept. Food Control. v. 12, p. 99-107, 2001a. 
KWAK, N.; JUKES, D. J. Functional foods. Part 2: the impact on current regulatory terminology. Food Control. v. 12, p. 109-117, 2001b.

LIN HE, M. S.; FERNANDEZ, M. L. Saturated fat and simple carbohydrates elevate plasma LDL cholesterol concentrations by specific alterations on hepatic cholesterol metabolism. Nutrition Research. v.18, n.6, p. 10031015, 1998.

LOPES, R. M., et al. Flavonóides. Biotecnologia: Ciência \& Desenvolvimento. p. 18-22, 2003.

MAZZA, G. Alimentos funcionales: aspectos bioquímicos y de processado. Zaragoza: Editora Acribia, 2000.

MUNRO, I. C. Soy isoflavones: A safety reviews. Internacional Life Sciences Institute. Nutricion Reviews. v. 61, n. 1, p. 1-33, 2003.

NEUMANN, P., et al. Alimentos saudáveis, alimentos funcionais, fármaco alimentos, nutracêuticos....você já ouviu falar? Higiene Alimentar. v. 14, p. 19-23, 2002.

NOONAN, W. P.; NOONAN, C. Legal requeriments for "functional foods" claims. Toxicology Letters. v. 150, p. 1924, 2004.

PIMENTEL, B. M. V.; FRANCKI, M.; GOLLÜCKE, B. P. Alimentos funcionais: introdução as principais substâncias bioativas em alimentos. São Paulo: Editora Varella, 2005.

REIG, A. L. C.; ANESTO, J. B. Prebióticos y probióticos, una Relación Beneficiosa. Instituto de Nutrición e Hiene de los Alimentos. Revista Cubana de Alimentação e Nutrição. v. 16, n. 1, p. 63-8, 2002.

RIBEIRO, E. P.; SERAVALLI, E. A. G. Química de alimentos. São Paulo: Editora Edgard Blucher: Instituto Mauá de Tecnologia, 2004. ISBN: 85-212-0326-8.

ROBERFROID, M. Functional food concept and its application to prebiotics. Digestive and Liver Disease. v. 34, Suppl. 2, p. 105-10, 2002.

RODRÍGUEZ, M. B. S.; MEgÍAS, S. M.; BAENA, B. M. Alimentos Funcionales y Nutrición óptima. Revista da Espanha de Salud Pública. v. 77, n. 3, p. 317-331, 2003.

SAAD, S. M. I. Probióticos e prebióticos: o estado da arte. Revista Brasileira de Ciências Farmacêuticas. v. 42, n. 1., p.1-16, 2006.

SALINAS, R. D. Alimentos e nutrição: introdução à bromatologia. 3. ed. Porto Alegre: Editora Artmed, 2002.

SALMINEN, S., et al. Demonstration of safety of probiotics-a review. International Journal of Food Microbiology. v. 44, p. 93-106, 1998.

SHAMI, N. J. I. E.; MOREIRA, E. A. M. Licopeno como agente antioxidante. Revista de Nutrição. v. 17, n. 2, p. 227-236, 2004.

SOARES, S. E. Ácidos fenólicos como antioxidantes. Revista de Nutrição. v. 15, n.1, p. 71-81, 2002.

SOUZA, P. H. M.; SOUZA NETO, M. H.; MAIA, G. A. Componentes funcionais nos alimentos. Boletim da SBCTA. v. 37, n. 2 , p. $127-135,2003$.

SPEER, K.; SPEER, I. K. The lipid fraction of the coffee bean. Brazilian Journal of Plantae Physiology. v.18, n. 1, p. 201-216, 2006.

STAHL, W.; SIES, H. Antioxidant activity of carotenoids. Molecular Aspects of Medicine. v. 24, n. 6, p. 345-351, 2003.

TAIPINA, M. S.; FONTS, M. A. S.; COHEN, V. H. Alimentos funcionais - nutracêuticos. Higiene Alimentar. v. 16, n. 100, p 28-29, 2002.

WALZEM, R. L. Functional Foods. Trends in Food Science and Technology. v. 15, p. 518, 2004. 
WANG, J.; MAZZA, G. Effects of anthocyanins and other phenolic compounds on the production of tumor necrosis factor $\alpha$ in LPSNFN- $\gamma$ - activated raw 264.7 macrophages. Journal Agricultural and Food Chemistry. v. 50, p. $4183-$ 4189, 2002. 